\title{
Gut microbiota composition in relation to the metabolic response to 12-week combined polyphenol supplementation in overweight men and women
}

Citation for published version (APA):

Most, J., Penders, J., Lucchesi, M., Goossens, G. H., \& Blaak, E. E. (2017). Gut microbiota composition in relation to the metabolic response to 12-week combined polyphenol supplementation in overweight men and women. European Journal of Clinical Nutrition, 71(9), 1040-1045. https://doi.org/10.1038/ejcn.2017.89

Document status and date:

Published: 01/09/2017

DOI:

10.1038/ejcn.2017.89

Document Version:

Publisher's PDF, also known as Version of record

\section{Document license:}

Taverne

Please check the document version of this publication:

- A submitted manuscript is the version of the article upon submission and before peer-review. There can be important differences between the submitted version and the official published version of record.

People interested in the research are advised to contact the author for the final version of the publication, or visit the DOI to the publisher's website.

- The final author version and the galley proof are versions of the publication after peer review.

- The final published version features the final layout of the paper including the volume, issue and page numbers.

Link to publication

\footnotetext{
General rights rights.

- You may freely distribute the URL identifying the publication in the public portal. please follow below link for the End User Agreement:

www.umlib.nl/taverne-license

Take down policy

If you believe that this document breaches copyright please contact us at:

repository@maastrichtuniversity.nl

providing details and we will investigate your claim.
}

Copyright and moral rights for the publications made accessible in the public portal are retained by the authors and/or other copyright owners and it is a condition of accessing publications that users recognise and abide by the legal requirements associated with these

- Users may download and print one copy of any publication from the public portal for the purpose of private study or research.

- You may not further distribute the material or use it for any profit-making activity or commercial gain

If the publication is distributed under the terms of Article $25 \mathrm{fa}$ of the Dutch Copyright Act, indicated by the "Taverne" license above, 
ORIGINAL ARTICLE

Gut microbiota composition in relation to the metabolic response to 12-week combined polyphenol supplementation in overweight men and women

\author{
J Most $^{1}$, J Penders ${ }^{2}$, M Lucchesi $^{2}$, GH Goossens $^{1}$ and EE Blaak ${ }^{1}$
}

BACKGROUND/OBJECTIVES: The intestinal microbiota may have a profound impact on host metabolism. As evidence suggests that polyphenols affect substrate utilization, the present study aimed to investigate the effects of polyphenol supplementation on intestinal microbiota composition in humans. Furthermore, we examined whether (changes in) gut microbiota composition may determine the metabolic response to polyphenol supplementation.

SUBJECTS/METHODS: In this randomized, double-blind, placebo (PLA)-controlled trial, 37 overweight and obese men and women (18 males/19 females, $37.8 \pm 1.6$ years, body mass index: $29.6 \pm 0.5 \mathrm{~kg} / \mathrm{m}^{2}$ ) received either epigallocatechin-3-gallate and resveratrol (EGCG+RES, 282 and $80 \mathrm{mg} /$ day, respectively) or PLA for 12 weeks. Before and after intervention, feces samples were collected to determine microbiota composition. Fat oxidation was assessed by indirect calorimetry during a high-fat mixed meal test ( $2.6 \mathrm{MJ}$, 61 energy\% fat) and skeletal muscle mitochondrial oxidative capacity by means of ex vivo respirometry on isolated skeletal muscle fibers. Body composition was measured by dual-energy X-ray absorptiometry.

RESULTS: Fecal abundance of Bacteroidetes was higher in men as compared with women, whereas other assessed bacterial taxa were comparable. EGCG+RES supplementation significantly decreased Bacteroidetes and tended to reduce Faecalibacterium prausnitzii in men ( $P=0.05$ and $P=0.10$, respectively) but not in women $(P=0.15$ and $P=0.77$, respectively). Strikingly, baseline Bacteroidetes abundance was predictive for the EGCG+RES-induced increase in fat oxidation in men but not in women. Other bacterial genera and species were not affected by EGCG+RES supplementation.

CONCLUSIONS: We demonstrated that 12-week EGCG+RES supplementation affected the gut microbiota composition in men but not in women. Baseline microbiota composition determined the increase in fat oxidation after EGCG+RES supplementation in men.

European Journal of Clinical Nutrition (2017) 71, 1040-1045; doi:10.1038/ejcn.2017.89; published online 7 June 2017

\section{INTRODUCTION}

The human intestinal microbiota consists of $10^{12}-10^{14}$ bacteria and may significantly impact health status. ${ }^{1}$ Although antibiotic or fecal transplantation studies provide important proof-of-principle evidence for the impact of the microbiota on host metabolism, 2,3 dietary interventions may offer a more feasible approach to manipulate gut microbiota. ${ }^{4}$

Changes in macronutrient composition have been shown to affect the intestinal microbiota ${ }^{5}$ and improve insulin sensitivity in patients with type 2 diabetes. ${ }^{6}$ Interestingly, polyphenols may induce beneficial metabolic effects, ${ }^{7-10}$ which may, at least partly, be mediated by alterations of the gut microbiota composition. For example, polyphenol-enriched products induced alterations in microbial composition and had beneficial effects on insulin sensitivity, ectopic fat storage and inflammation ${ }^{11-14}$ in rodents. In line, supplementation of the polyphenols epigallocatechin-3gallate (EGCG) and resveratrol (RES) has been shown to improve markers of insulin sensitivity, inflammation and fat oxidation in humans. ${ }^{7,9,15}$ Although these effects have largely been attributed to direct effects on peripheral organs, importantly, however, our gut microbes may have an important role in the conversion of polyphenols to bioactive compounds. ${ }^{16}$ Furthermore, polyphenols may modify the gut microbial composition, thereby acting as prebiotics. ${ }^{17}$ Until now, studies that have examined the effects of polyphenols on gut microbiota composition and assessed the involvement of the intestinal microbiota in effects on peripheral metabolism are scarce. ${ }^{18}$

Here we aimed to investigate the effects of combined EGCG and RES supplementation for 12 weeks on gut microbiota composition in humans. Therefore, we measured fecal abundances of key microbial phyla and functional groups before and after 12-week supplementation with either EGCG+RES or placebo (PLA) in overweight and obese men and women. Second, we examined whether (changes in) microbiota composition may underlie the EGCG+RES-induced improvement in lipid oxidation and mitochondrial oxidative capacity in humans that we have previously found. ${ }^{10}$

\section{MATERIALS AND METHODS}

Study design

In this randomized, double-blind, PLA-controlled study, which was a substudy of a larger study designed to investigate the effects of polyphenol supplementation on insulin sensitivity, fat oxidation and skeletal muscle oxidative capacity, ${ }^{10}$ subjects received a combination of EGCG and

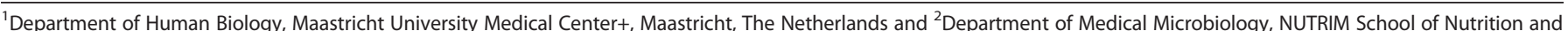

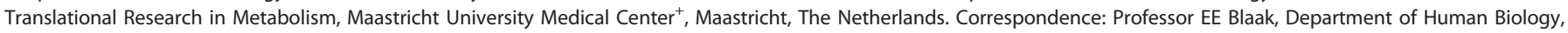
Maastricht University Medical Center ${ }^{+}$, PO BOX 616, Maastricht 6200 MD The Netherlands.

E-mail: e.blaak@maastrichtuniversity.nl

Received 25 October 2016; revised 13 March 2017; accepted 30 March 2017; published online 7 June 2017
} 
RES supplements (EGCG+RES; 282 and $80 \mathrm{mg} /$ day, respectively) or PLA (partly hydrolyzed microcrystalline cellulose-filled supplements) for a period of 12 weeks. Body composition was determined by dual-energy X-ray absorptiometry (VitaK, Maastricht, The Netherlands).

Abundances of fecal microbiota were measured using stool samples. Sample collection and clinical measurements were performed before and in the last week of supplementation. Subjects were instructed to maintain their habitual lifestyle pattern throughout the study. Control visits were scheduled at weeks 2, 4 and 8 of intervention. In weeks 0,4 and 12, subjects were asked to fill in a 3-day food intake record in order to assess dietary intake.

\section{Subjects}

Forty-two untrained ( $<3 \mathrm{~h}$ organized sports activities per week), weightstable ( $<2 \mathrm{~kg}$ body weight change 3 months prior to inclusion), overweight/obese (body mass index $>25 \mathrm{~kg} / \mathrm{m}^{2}$ ) but otherwise healthy Caucasian men and women (1:1) between 20 and 50 years with normal glucose tolerance and normal blood pressure were included in this study. Subjects were not allowed to use any antibiotics or medication/ supplements that might interfere with insulin sensitivity and substrate metabolism for 3 months before entering the study. Daily intake of caffeine ( $<600 \mathrm{mg}$ ), green tea ( $<3$ cups) and alcohol $(<20 \mathrm{~g}$ ) had to be limited. Detailed inclusion and exclusion criteria for study participants were published earlier. ${ }^{10}$ All subjects gave written informed consent for participation in this study, which was reviewed and approved by the local Medical Ethical Committee of Maastricht University Medical Centre ${ }^{+}$. All procedures were according to the Declaration of Helsinki.

\section{Gut microbiota composition}

DNA isolation. Metagenomic DNA was isolated as described previously. ${ }^{19}$ Briefly, approximately $200 \mathrm{mg}$ of feces was added to a 2-ml vial containing $0.5 \mathrm{~g}$ zirconia beads $(0.1 \mathrm{~mm})$ and 4 glass beads ( $3 \mathrm{~mm}$ ) (Biospec, Bartlesville, OK, USA) and $1.2 \mathrm{ml}$ of PSP lysis buffer (Stractec Biomedical, Berlin, Germany). Samples were treated in a Magna Lyser at $5.5 \mathrm{~ms}$ in 3 cycles of $1 \mathrm{~min}$ and cooled on ice in between cycles. Subsequently, the DNA isolation was continued using the PSP SPIN Stool DNA Plus Kit as per the manufacturer's instructions and finally eluted in $200 \mu$ l.

Microbial analysis using real-time PCR assays. DNA from all fecal samples was subjected to real-time PCR assays for the enumeration of the bacterial phyla $\gamma$-Proteobacteria, Actinobacteria, Firmicutes and Bacteroidetes, as well as for the quantification of Akkermansia muciniphila, Faecalibacterium prausnitizii, sulfate-reducing bacteria, acetogenic bacteria and the archeon Methanobrevibacter smithii (primers and probes are listed in Table 1).

For the enumeration of $\gamma$-Proteobacteria, Actinobacteria, Bacteroidetes, A. muciniphila, F. prausnitzii, sulfate-reducing bacteria and acetogens, realtime detection of PCR products was conducted with SYBR Green I. The PCRs were conducted in a total volume of $25 \mu \mathrm{l}$, containing $1 \times$ iQ SYBR
Green Supermix (Bio-Rad Laboratories Inc., Hercules, ON, Canada), $400 \mathrm{~nm}$ of both primers ${ }^{20-24}$ and $2 \mu \mathrm{l}$ of purified and 10 -fold diluted target DNA. Amplification, melting curve analysis and detection were conducted with the MiQ-Single-Color real-time PCR Detection System (Bio-Rad).

The $5^{\prime}$-nuclease technique was used for the detection of Firmicutes and M. smithii as described previously. ${ }^{25}$ PCRs were conducted in a total volume of $25 \mu \mathrm{l}$, containing $1 \times$ ABsolute qPCR Mix (ABgene, Hamburg, Germany), $200 \mathrm{~nm}$ of both primers and $200 \mathrm{~nm}$ TaqMan probe and $2 \mu \mathrm{l}$ of purified and 10-fold diluted target DNA. The amplification and detection were conducted with an Applied Biosystems Prism 7900 sequence detection system (Applied Biosystems, Waltham, MA, USA). Serial dilutions of plasmid constructs containing the target sequences were used to create calibration curves for quantification.

Fat oxidation and ex vivo mitochondrial oxidative capacity As described elsewhere, ${ }^{10}$ a high-fat mixed meal test (2.6 MJ, 61.2 energy\% fat) was performed to assess whole-body energy expenditure and fat oxidation before $(t=0 \mathrm{~min})$ and for $4 \mathrm{~h}$ after ingestion of the high-fat mixed meal test by means of indirect calorimetry, using an open-circuit ventilated hood system (Omnical, Maastricht University, Maastricht, The Netherlands). Mitochondrial oxidative capacity was measured by ex vivo high-resolution respirometry (Oroboros Instruments, Innsbruck, Austria) on permeabilized skeletal muscle fibers that were isolated from biopsies $(m$. vastus lateralis), which were collected under fasting conditions under local anesthesia. $^{26}$

\section{Supplements}

The supplements were commercially available and kindly provided by Pure Encapsulations Inc. (Sudbury, MA, USA). All capsules were manufactured, tested and checked in accordance to standards of EU GMP requirements.

EGCG capsules contained 94\% EGCG (141 mg per capsule) and RES capsules $20 \%$ trans-resveratrol (40 mg per capsule). Two kinds of PLA capsules (microcrystalline cellulose) were used for blinding. Capsules were packed into white opaque boxes, labeled per subject without indication of the content. After completion of the study, returned capsules were counted for compliance.

\section{Statistics}

All data are expressed as mean \pm s.e.m. Log10 DNA copies for a given microbial group/species per gram of wet weight feces were calculated for each stool sample from the Ct-values using the constructed calibration curves.

Analyses were performed by gender because of differences in bacterial composition. Differences between supplementation groups were analyzed using repeated-measures analysis of variance with time and supplementation as factors. Regression analysis was performed to assess relations between baseline abundances or intervention-induced changes $\left(\Delta_{\text {Week }} 12\right.$-Week o $)$ in the abundance of microbial taxa and changes in fat

Table 1. Baseline subjects' characteristics

\begin{tabular}{|c|c|c|c|c|c|c|}
\hline & Men $(\mathrm{n}=18)$ & Women $(\mathrm{n}=19)$ & $\mathrm{P}$ (gender) & $P L A(\mathrm{n}=19)$ & $E G C G+R E S(\mathrm{n}=18)$ & $\mathrm{P}$ (group) \\
\hline Age, years & $40.2 \pm 2.1$ & $35.6 \pm 2.4$ & 0.17 & $39.5 \pm 2.3$ & $36.1 \pm 2.3$ & 0.30 \\
\hline Weight, kg & $96.3 \pm 3.5$ & $83.2 \pm 2.2$ & 0.00 & $87.1 \pm 2.9$ & $92.2 \pm 3.5$ & 0.28 \\
\hline Waist-hip-ratio & $0.94 \pm 0.02$ & $0.81 \pm 0.02$ & 0.00 & $0.88 \pm 0.02$ & $0.87 \pm 0.02$ & 0.66 \\
\hline Diastolic BP, mm Hg & $118 \pm 2$ & $113 \pm 2$ & 0.15 & $114 \pm 3$ & $117 \pm 2$ & 0.30 \\
\hline Systolic BP, mm Hg & $77 \pm 2$ & $75 \pm 2$ & 0.59 & $77 \pm 2$ & $76 \pm 2$ & 0.83 \\
\hline Glucose, fasted, $\mathrm{mmol} / \mathrm{l}$ & $5.29 \pm 0.05$ & $5.02 \pm 0.1$ & 0.03 & $5.11 \pm 0.08$ & $5.19 \pm 0.09$ & 0.52 \\
\hline Body fat, $\%$ & $24.4 \pm 0.9$ & $36.6 \pm 0.9$ & 0.00 & $29.7 \pm 1.9$ & $31.6 \pm 1.4$ & 0.45 \\
\hline Adiponectin, mg/ml & $6.42 \pm 0.49$ & $11.04 \pm 0.76$ & 0.00 & $8.84 \pm 0.88$ & $8.74 \pm 0.82$ & 0.93 \\
\hline Leptin, ng/ml & $10.8 \pm 1.5$ & $30.3 \pm 3$ & 0.00 & $21.7 \pm 4.1$ & $19.8 \pm 2.4$ & 0.68 \\
\hline Interleukin-6, pg/ml & $0.79 \pm 0.14$ & $0.88 \pm 0.14$ & 0.63 & $0.89 \pm 0.17$ & $0.77 \pm 0.07$ & 0.52 \\
\hline Interleukin-8, pg/ml & $10.9 \pm 0.7$ & $8.1 \pm 0.7$ & 0.01 & $9.1 \pm 0.6$ & $9.8 \pm 0.9$ & 0.55 \\
\hline TNF- $\alpha, p g / m l$ & $3.3 \pm 0.22$ & $2.3 \pm 0.08$ & 0.00 & $2.88 \pm 0.22$ & $2.69 \pm 0.18$ & 0.49 \\
\hline
\end{tabular}


oxidation and muscle mitochondrial oxidative capacity in the EGCG+RES group (men, $n=7$; women, $n=7$ ). Microbial abundances and EGCG+RESinduced changes in microbial abundances were used as independent variable and changes in fat oxidation and mitochondrial oxidative capacity as dependent variables. Variables were normally distributed and the mean of the dependent variable ((week $0+$ week 12)/2) was included in the model to correct for regression to the mean. Statistics was carried out using SPSS 19.0 (IBM Corporation, Armonk, NY, USA) for Macintosh. $P<0.05$ of the interaction term (time $\times$ supplementation) and for the standardized $\beta$ within a regression term was considered as statistically significant.

\section{RESULTS}

Subjects characteristics

Forty-two overweight and obese but otherwise healthy men and women volunteered to participate in this study, of which four subjects (three men, one women) dropped out (one went traveling abroad, one was re-employed at full-time job, one did

Table 2. Baseline abundances of bacterial phyla and species

\begin{tabular}{lccc}
\hline & Men & Women & $P$ \\
\hline$\gamma$-Proteobacteria, log10 & $11.29 \pm 0.11$ & $10.93 \pm 0.14$ & 0.05 \\
Actinobacteria, log10 & $11.5 \pm 0.08$ & $11.55 \pm 0.12$ & 0.77 \\
Akkermansia muciniphila, log10 & $8.77 \pm 0.45$ & $9.71 \pm 0.36$ & 0.11 \\
Firmicutes, log10 & $12.33 \pm 0.06$ & $12.34 \pm 0.06$ & 0.83 \\
Bacteroidetes, log10 & $13.21 \pm 0.07$ & $12.88 \pm 0.06$ & $\mathbf{0 . 0 0}$ \\
Methanobrevibacter smithii, log10 & $9.38 \pm 0.33$ & $8.95 \pm 0.36$ & 0.40 \\
Faecalibacterium prausnitzii, log10 & $12.03 \pm 0.09$ & $11.98 \pm 0.1$ & 0.71 \\
Sulfate-reducing bacteria, log10 & $10.54 \pm 0.27$ & $10.15 \pm 0.41$ & 0.43 \\
Acetogen bacteria, log10 & $10.83 \pm 0.06$ & $10.88 \pm 0.06$ & 0.58 \\
B/F ratio & $9.4 \pm 1.4$ & $3.8 \pm 0.5$ & $\mathbf{0 . 0 0}$ \\
$\gamma$-Proteobacteria, \% & $1.4 \pm 0.3$ & $1.3 \pm 0.2$ & 0.61 \\
Actinobacteria, \% & $2.5 \pm 0.6$ & $6 \pm 1.6$ & $\mathbf{0 . 0 5}$ \\
Akkermansia muciniphila, \% & $0.2 \pm 0.1$ & $0.7 \pm 0.4$ & 0.17 \\
Firmicutes, \% & $12.5 \pm 1.6$ & $22.7 \pm 2$ & $\mathbf{0 . 0 0}$ \\
Bacteroidetes, \% & $83.3 \pm 2$ & $69.3 \pm 2.9$ & $\mathbf{0 . 0 0}$ \\
\hline
\end{tabular}

Abbreviation: B/F ratio, Bacteroidetes/Firmicutes ratio. Absolute (log10) and relative (\%) abundances of bacterial phyla and species in $1 \mathrm{~g}$ wet weight of fecal samples. $P$-value for statistical difference between gender. Values are given as mean \pm s.e.m. Bold values are statistically significant (all $P<0.05$ ). not comply with supplementation and one substantially changed diet and/or physical activity pattern). In addition, one female subject was excluded from analyses because of reported diarrhea. Characteristics of the 37 subjects who completed the study are summarized in Table 1. There were no significant differences between the EGCG+RES and PLA groups with respect to baseline characteristics. Men had higher fasting plasma glucose and inflammatory cytokine levels (Table 1), but leptin and adiponectin concentrations were, as expected, significantly lower.

Compliance was confirmed by counting returned supplements and increased plasma concentrations of EGCG, RES and dihydroRES after the intervention in the EGCG+RES group as reported earlier. ${ }^{10}$ Energy intake and macronutrient composition were not significantly changed in the EGCG+RES and PLA groups over time.

\section{Gender differences in microbiota composition}

Fecal abundances of microbial groups were different between men and women (Table 2). Absolute abundances of $\gamma$-Proteobacteria $(P=0.05)$ and Bacteroidetes $(P<0.01)$ were higher in men as compared with women, while other phyla and species were comparable. The relative abundance of Bacteroidetes, expressed as the percentage of the five dominant phyla, was higher in men than in women $(P<0.01)$, while Firmicutes $(P<0.01)$ and Actinobacteria $(P=0.04)$ abundance was relatively lower in men (Table 2).

EGCG+RES supplementation decreased bacteroidetes abundance in men but not in women

In men, EGCG+RES supplementation significantly reduced the abundance of Bacteroidetes $(P=0.05)$ and tended to decrease F. prausnitizii abundance as compared with PLA ( $P=0.10$, Table 3$)$. However, these changes were not observed in women (Table 4). The abundance of Firmicutes, Actinobacteria, $y$-Proteobacteria and A. muciniphila (phylum Verrucomicrobiae), sulfate-reducing bacteria, acetogenic bacteria and the archeon M. smithii were not significantly affected by the intervention neither in men (Table 3) nor in women (Table 4).

Table 3. The effects of 12-week EGCG+RES supplementation on the abundance of bacterial phyla and species as compared with PLA in men

\begin{tabular}{|c|c|c|c|c|c|}
\hline \multirow[t]{2}{*}{ Men } & \multicolumn{2}{|c|}{$P L A(\mathrm{n}=10)$} & \multicolumn{2}{|c|}{$E G C G+R E S(\mathrm{n}=8)$} & \multirow[t]{2}{*}{$\mathrm{P}$} \\
\hline & Week 0 & Week 12 & Week 0 & Week 12 & \\
\hline$\gamma$-Proteobacteria, $\log 10$ & $11.31 \pm 0.16$ & $11.2 \pm 0.09$ & $11.26 \pm 0.13$ & $10.95 \pm 0.23$ & 0.49 \\
\hline Actinobacteria, $\log 10$ & $11.51 \pm 0.1$ & $11.44 \pm 0.07$ & $11.5 \pm 0.13$ & $11.32 \pm 0.2$ & 0.59 \\
\hline Akkermansia muciniphila, log10 & $0.38 \pm 0.23$ & $0.11 \pm 0.07$ & $0.04 \pm 0.03$ & $0.01 \pm 0.01$ & 0.59 \\
\hline Firmicutes, $\log 10$ & $12.31 \pm 0.09$ & $12.33 \pm 0.07$ & $12.35 \pm 0.07$ & $12.17 \pm 0.15$ & 0.28 \\
\hline Bacteroidetes, $\log 10$ & $13.18 \pm 0.09$ & $13.19 \pm 0.07$ & $13.25 \pm 0.11$ & $12.94 \pm 0.14$ & 0.05 \\
\hline Methanobrevibacter smithii, $\log 10$ & $9.31 \pm 0.44$ & $8.8 \pm 0.42$ & $9.56 \pm 0.58$ & $8.57 \pm 0.72$ & 0.75 \\
\hline Faecalibacterium prausnitzii, log10 & $11.99 \pm 0.13$ & $12.02 \pm 0.13$ & $12.08 \pm 0.12$ & $11.64 \pm 0.3$ & 0.10 \\
\hline Sulfate-reducing bacteria, $\log 10$ & $10.7 \pm 0.24$ & $10.57 \pm 0.25$ & $10.34 \pm 0.54$ & $9.38 \pm 0.88$ & 0.14 \\
\hline Acetogen bacteria, $\log 10$ & $10.76 \pm 0.1$ & $10.77 \pm 0.06$ & $10.92 \pm 0.06$ & $10.82 \pm 0.16$ & 0.47 \\
\hline $\mathrm{B} / \mathrm{F}$ ratio & $8.8 \pm 1.6$ & $8.9 \pm 1.5$ & $10.1 \pm 2.7$ & $6.4 \pm 0.9$ & 0.22 \\
\hline$\gamma$-Proteobacteria, \% & $1.7 \pm 0.4$ & $1.1 \pm 0.2$ & $1.1 \pm 0.3$ & $1.2 \pm 0.4$ & 0.30 \\
\hline Actinobacteria, \% & $2.8 \pm 1$ & $1.7 \pm 0.3$ & $2 \pm 0.5$ & $2.8 \pm 0.7$ & 0.19 \\
\hline Akkermansia muciniphila, \% & $0.4 \pm 0.2$ & $0.1 \pm 0.1$ & $0 \pm 0$ & $0 \pm 0$ & 0.37 \\
\hline Firmicutes, \% & $12.6 \pm 2.1$ & $13.5 \pm 2.9$ & $12.5 \pm 2.7$ & $14.5 \pm 1.8$ & 0.79 \\
\hline Bacteroidetes, \% & $82.5 \pm 2.9$ & $83.6 \pm 3.2$ & $84.3 \pm 2.9$ & $81.5 \pm 1.8$ & 0.38 \\
\hline
\end{tabular}

Abbreviation: B/F ratio, Bacteroidetes/Firmicutes ratio. Absolute (log10) and relative (\%) abundances of bacterial phyla and species in $1 \mathrm{~g}$ wet weight of fecal samples. $P$-value for statistical significance for time $\times$ treatment interactions. Values are given as mean \pm s.e.m. Bold values are statistically significant (all $P<0.05$ ). 
Table 4. The effects of 12-week EGCG+RES supplementation on the abundance of bacterial phyla and species as compared with PLA in women

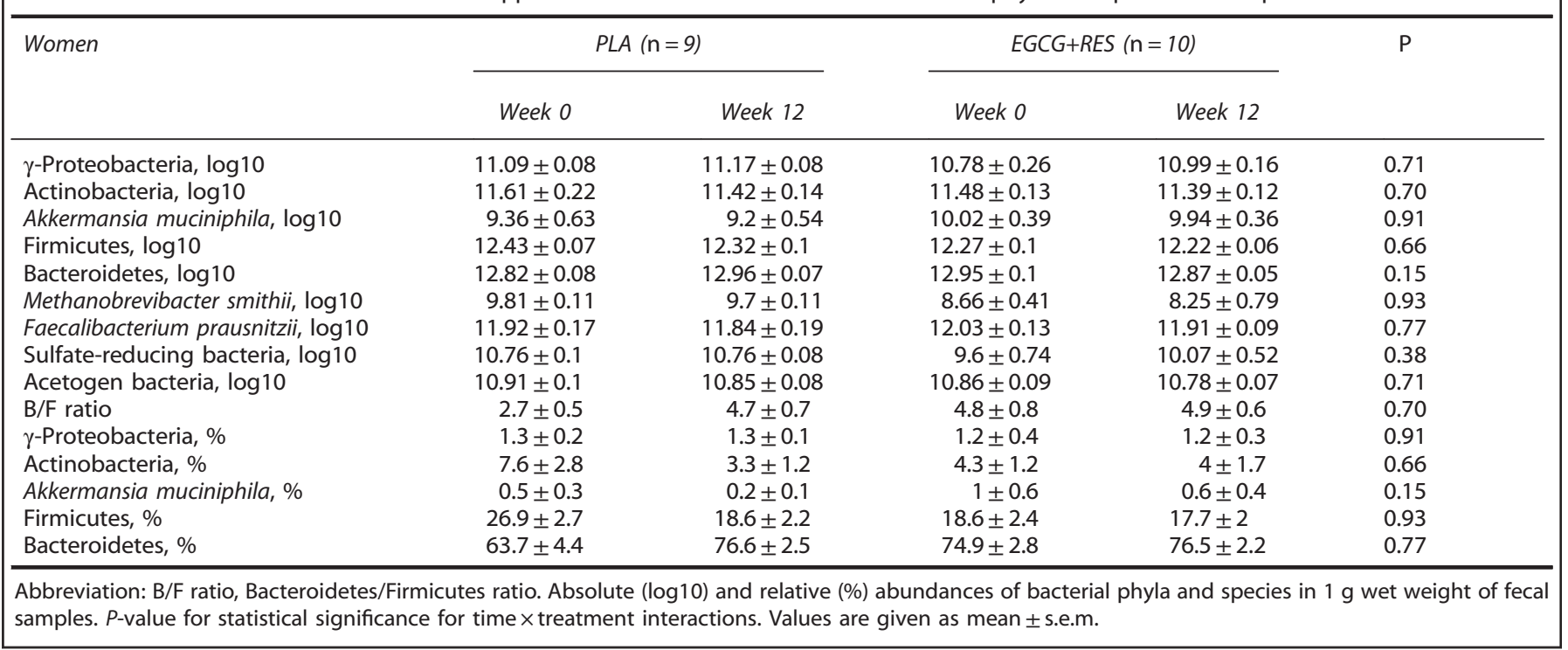

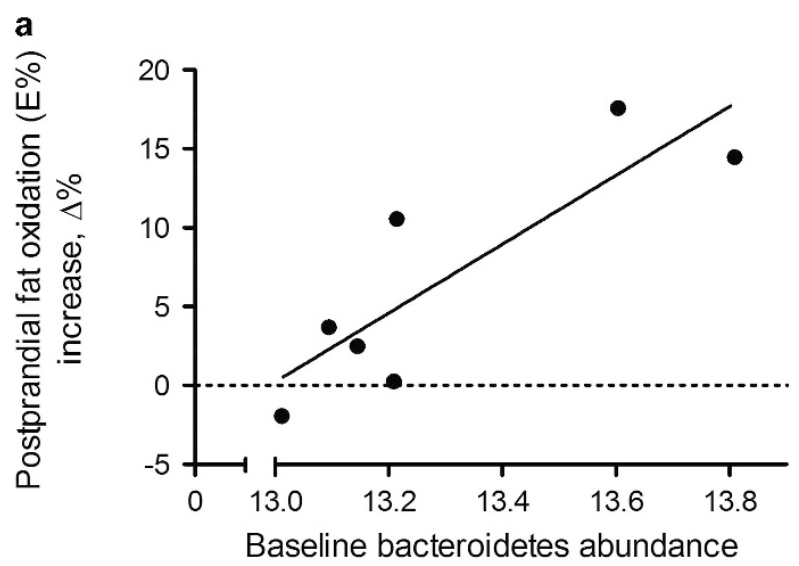

\section{b}

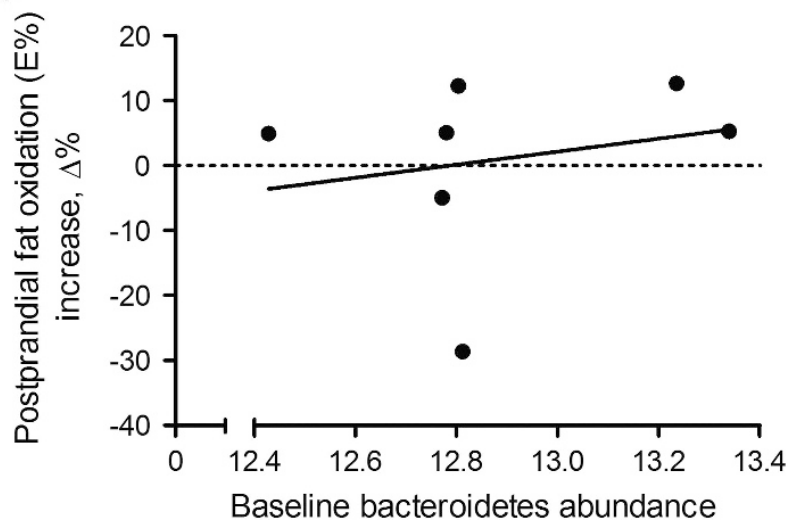

Figure 1. Correlation between baseline Bacteroidetes abundance and the EGCG+RES-induced increase in postprandial fat oxidation. Baseline Bacteroidetes abundance significantly correlated with (a) the increase in postprandial fat oxidation in men $(n=7, P=0.03)$ but (b) not in women $(n=7, P=0.68)$. The increase in fat oxidation is expressed as $\Delta_{\text {Week } 12-\text { Week } 0 \text {, calculated }}$ from the relative contribution of fat oxidation to total energy expenditure (\%).
Fat oxidation and mitochondrial oxidative capacity

The effects of EGCG+RES supplementation on fat oxidation and mitochondrial oxidative capacity have been reported previously for the total group of participants. ${ }^{10}$ Briefly, fat oxidation, expressed as the percentage of energy expenditure, was increased in the EGCG+RES group as compared with PLA during fasting $(P=0.03)$ and postprandial conditions after consumption of a high-fat mixed meal (2.6 MJ, 61 energy $\%$ fat, $P=0.02)$. In line, skeletal muscle mitochondrial oxidative capacity, assessed using ex vivo high-resolution respirometry, was increased after EGCG + RES supplementation versus PLA $(P=0.01)$.

Relation between (changes in) microbiota composition and fat oxidation following EGCG+RES supplementation

Strikingly, baseline Bacteroidetes abundance was significantly correlated with the EGCG+RES-induced increase in postprandial fat oxidation (area under the receiver-operating characteristic curve (AUC)) $(r=0.855, P=0.01$, Figure $1 \mathrm{a})$ in men. This correlation remained significant after adjustment for mean fat oxidation

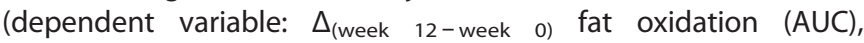
independent variables: Bacteroidetes abundance week $_{0}$, Std. $\beta=0.865, P=0.03$; mean $_{\text {(week } 0 \text {, week 12) }}$ fat oxidation (AUC), Std. $\beta=-0.057, P=0.84)$. Moreover, the Bacteroidetes/Firmicutes ratio was significantly correlated with postprandial fat oxidation $(r=0.813, P=0.03)$. The abundance of Firmicutes was not related to changes in fat oxidation $(r=-0.191, P=0.68)$. Other bacterial groups showed no significant association with fat oxidation (data not shown). The EGCG+RES-induced reduction in the abundance of Bacteroidetes and F. prausnitzii in men was, however, not related to the observed changes in fat oxidation und oxidative capacity following EGCG+RES supplementation as compared with PLA. Likewise, no significant relationship was found between (changes in) gut microbiota composition and skeletal muscle mitochondrial oxidative capacity.

In women, no significant associations were observed between (changes in) gut microbiota composition and EGCG+RES-induced effects on fasting and postprandial fat oxidation (Figure $1 \mathrm{~b}$ for baseline Bacteroidetes and postprandial fat oxidation). 


\section{DISCUSSION}

Dietary polyphenols have been associated with a variety of health benefits related to chronic metabolic and inflammatory diseases such as obesity, diabetes and cardiovascular diseases. ${ }^{7,9,15}$ Accumulating evidence indicates that the gut microbiome influences metabolic health, ${ }^{2,3}$ but very few studies have examined the effects of dietary interventions on the gut microbiota. Interestingly, polyphenol supplementation may affect gut microbiota composition and, consequently, metabolic health. ${ }^{18,27}$ Here we report that men show a pronounced higher abundance of Bacteroidetes as compared with women. Furthermore, 12 weeks of EGCG+RES supplementation decreased the fecal abundance of Bacteroidetes and tended to reduce $F$. prausnitzii in men, whereas no alterations were found in women. Interestingly, our data indicate that baseline Bacteroidetes abundance seems to be involved in the EGCG+RES-induced increase in fat oxidation in men but not in women.

Previous studies have demonstrated gender differences in gut microbiota composition in humans, ${ }^{4,28}$ which may at least partly be explained by differences in sex hormones. ${ }^{29,30}$ Alternatively, early-life acquisition (use of antibiotics) ${ }^{31}$ and lifestyle (local environment, eating and defecation pattern) ${ }^{32,33}$ may underlie inter-individual variation and may also contribute to genderspecific microbiota composition. The present study, therefore, examined the effects of prolonged polyphenol supplementation on gut microbiota composition in a gender-specific manner. Interestingly, we found that EGCG+RES supplementation reduced the abundance of Bacteroidetes but not Firmicutes in men, which resulted in a decreased Bacteroidetes/Firmicutes ratio following 12-week EGCG+RES supplementation. In line with our findings, polyphenols seem to have antimicrobial characteristics, ${ }^{34}$ most likely because of their chelating properties on iron, which is an important oligo-element for heme-utilizing bacteria. ${ }^{35}$ In contrast to most previous studies (reviewed in Duenas et al. ${ }^{17}$ and Cardona et $a .^{27}$ ), we did not observe any polyphenol-induced prebiotic effects on Firmicutes abundance in overweight and obese humans.

Next we investigated whether microbial species and phyla relate to host metabolism, as has previously been suggested. ${ }^{4,18,28,32,36}$ Intriguingly, we found that a high abundance of Bacteroidetes at baseline was correlated with a more pronounced EGCG+RES-induced increase in postprandial fat oxidation in men.

Only $5-10 \%$ of the ingested polyphenols are absorbed in the small intestine, ${ }^{27}$ and the majority is transferred to the colon where they are subjected to microbial metabolism. ${ }^{37}$ Interestingly, the produced polyphenolic metabolites show a high interindividual variability, which may be dependent on the gut microbiota. ${ }^{38}$ These metabolites seem to have distinct and/or synergistic effects on peripheral tissues. ${ }^{39,40}$ Bacteroidetes contain more glycandegrading enzymes ${ }^{41}$ and may therefore facilitate diffusion of polyphenols and/or related metabolites through the intestinal barrier, thereby enhancing bioavailability. Although our data should be interpreted with caution, it is tempting to postulate that a high baseline abundance of Bacteroidetes might allow a more pronounced improvement in fat oxidation following polyphenol supplementation. In fact, it has been proposed earlier that metabolic health status might determine the effect of polyphenol supplementation on host metabolism. ${ }^{42,43}$ Bacteroidetes abundance appears to be related to markers of impaired metabolic health. ${ }^{44}$ Moreover, Bacteroidetes abundance was related to low fecal short-chain fatty acid concentrations, ${ }^{45}$ which may stimulate fat oxidation in overweight humans. ${ }^{46}$ Noteworthy, in the present study, a higher abundance of Bacteroidetes in men was paralleled by a more unhealthy metabolic profile (increased fasting glucose and inflammatory markers) as compared with women, which might support this notion.

Changes in microbial composition after pharmacological interventions have been related to changes in host physiology. ${ }^{2,3}$ In line, polyphenol supplementation in rodents reduced adipose tissue mass and ectopic fat accumulation, insulin resistance and inflammation, and these improvements were related to changes in microbiota composition. ${ }^{11-13}$ In the present study, however, we did not find significant correlations between the changes in gut microbiota composition and other metabolic parameters beside fat oxidation after EGCG+RES supplementation. Queipo-Ortuño et $a l^{18}$ have reported previously that effects of red wine polyphenol supplementation on blood pressure, plasma triacylglycerol, cholesterol and C-reactive protein concentrations were linked to changes in microbial composition. Thus the ability of microbiota to mediate effects on physiological parameters clearly warrants further investigation.

The present findings in women should be interpreted with some caution, as we did not obtain information on the phase of the menstrual cycle. Moreover, the use of oral contraceptives (11 out of the 19 female participants) may have influenced substrate metabolism ${ }^{47}$ and intestinal microbiota composition, as has already been reported for vaginal microbiota. ${ }^{48}$ Finally, although determination of phyla abundances has been used as valuable indicator of the impact of microbiota on substrate metabolism, ${ }^{36}$ a detailed microbial phenotyping using state-of-the-art next-generation sequencing may provide additional insight into relevant bacterial species in future studies. $^{49}$ Importantly, within the phyla Bacteroidetes, different genera, Bacteroides and Prevotella, do have different metabolic traits and define a host's enterotype. ${ }^{5,50}$

In conclusion, we demonstrated that overweight and obese men and women differ in their intestinal microbiota and in their susceptibility to intervention effects. Whereas EGCG+RES supplementation for 12 weeks reduced abundance of Bacteroidetes in men, no effects were observed in women. Furthermore, Bacteroidetes abundance at baseline was a significant predictor for the EGCG+RES-induced increase in fat oxidation in men. Future studies are warranted to further explore gender differences in gut microbiota composition and its relationship with metabolic outcome after interventions. Furthermore, state-of-the-art sequencing techniques to determine microbiota composition should be combined with metabolomics approaches to assess polyphenol metabolite profiles to obtain better insight into interindividual variability in the response to polyphenol supplementation on metabolic health in humans.

\section{CONFLICT OF INTEREST}

The authors declare no conflict of interest.

\section{ACKNOWLEDGEMENTS}

We thank the study participants and Pure Encapsulations Inc. for provision of the supplements. This study was funded by the ALPRO foundation.

\section{AUTHOR CONTRIBUTIONS}

JM, GHG and EEB designed the study. JM performed the experiments and analyzed the data. JM wrote the manuscript. JM, JP, ML, GHG and EEB revised the content of the manuscript and approved the manuscript for publication.

\section{REFERENCES}

1 Clemente JC, Ursell LK, Parfrey LW, Knight R. The impact of the gut microbiota on human health: an integrative view. Cell 2012; 148: 1258-1270.

2 Vrieze A, Out C, Fuentes S, Jonker L, Reuling I, Kootte RS et al. Impact of oral vancomycin on gut microbiota, bile acid metabolism, and insulin sensitivity. J Hepatol 2014; 60: 824-831.

3 Vrieze A, Van Nood E, Holleman F, Salojarvi J, Kootte RS, Bartelsman JF et al. Transfer of intestinal microbiota from lean donors increases insulin sensitivity in individuals with metabolic syndrome. Gastroenterology 2012; 143: 913-916.e7. 
4 Bolnick DI, Snowberg LK, Hirsch PE, Lauber CL, Org E, Parks B et al. Individual diet has sex-dependent effects on vertebrate gut microbiota. Nat Commun 2014; 5: 4500 .

5 Wu GD, Chen J, Hoffmann C, Bittinger K, Chen YY, Keilbaugh SA et al. Linking long-term dietary patterns with gut microbial enterotypes. Science 2011; 334: 105-108.

6 Chandalia M, Garg A, Lutjohann D, von Bergmann K, Grundy SM, Brinkley U. Beneficial effects of high dietary fiber intake in patients with type 2 diabetes mellitus. N Engl J Med 2000; 342: 1392-1398.

7 Bogdanski P, Suliburska J, Szulinska M, Stepien M, Pupek-Musialik D, Jablecka A. Green tea extract reduces blood pressure, inflammatory biomarkers, and oxidative stress and improves parameters associated with insulin resistance in obese, hypertensive patients. Nutr Res 2012; 32: 421-427.

8 Most J, Goossens GH, Jocken JW, Blaak EE. Short-term supplementation with a specific combination of dietary polyphenols increases energy expenditure and alters substrate metabolism in overweight subjects. Int J Obes (Lond) 2014; 38: 698-706.

9 Timmers S, Konings E, Bilet L, Houtkooper RH, van de Weijer T, Goossens GH et al. Calorie restriction-like effects of 30 days of resveratrol supplementation on energy metabolism and metabolic profile in obese humans. Cell Metab 2011; 14: 612-622.

10 Most J, Timmers S, Warnke I, Jocken JW, van Boekschoten M, de Groot $\mathrm{P}$ et al. Combined epigallocatechin-3-gallate and resveratrol supplementation for $12 \mathrm{wk}$ increases mitochondrial capacity and fat oxidation, but not insulin sensitivity, in obese humans: a randomized controlled trial. Am J Clin Nutr 2016; 104: 215-227.

11 Qiao Y, Sun J, Xia S, Tang X, Shi Y, Le G. Effects of resveratrol on gut microbiota and fat storage in a mouse model with high-fat-induced obesity. Food Funct 2014; 5: 1241-1249.

12 Anhe FF, Roy D, Pilon G, Dudonne S, Matamoros S, Varin TV et al. A polyphenolrich cranberry extract protects from diet-induced obesity, insulin resistance and intestinal inflammation in association with increased Akkermansia spp. population in the gut microbiota of mice. Gut 2015; 64: 872-883.

13 Roopchand DE, Carmody RN, Kuhn P, Moskal K, Rojas-Silva P, Turnbaugh PJ et al. Dietary polyphenols promote growth of the gut bacterium Akkermansia muciniphila and attenuate high fat diet-induced metabolic syndrome. Diabetes 2015; 64: 2847-2858.

14 Dao TM, Waget A, Klopp P, Serino M, Vachoux C, Pechere L et al. Resveratrol increases glucose induced GLP-1 secretion in mice: a mechanism which contributes to the glycemic control. PLoS One 2011; 6: e20700.

15 Brown AL, Lane J, Holyoak C, Nicol B, Mayes AE, Dadd T. Health effects of green tea catechins in overweight and obese men: a randomised controlled crossover trial. Br J Nutr 2011; 106: 1880-1889.

16 Tomas-Barberan FA, Selma MV, Espin JC. Interactions of gut microbiota with dietary polyphenols and consequences to human health. Curr Opin Clin Nutr Metab Care 2016; 19: 471-476.

17 Duenas M, Munoz-Gonzalez I, Cueva C, Jimenez-Giron A, Sanchez-Patan F, SantosBuelga $C$ et al. A survey of modulation of gut microbiota by dietary polyphenols. Biomed Res Int 2015; 2015: 850902.

18 Queipo-Ortuno Ml, Boto-Ordonez M, Murri M, Gomez-Zumaquero JM, ClementePostigo M, Estruch $\mathrm{R}$ et al. Influence of red wine polyphenols and ethanol on the gut microbiota ecology and biochemical biomarkers. Am J Clin Nutr 2012; 95: 1323-1334.

19 Tedjo DI, Jonkers DM, Savelkoul PH, Masclee AA, van Best N, Pierik MJ et al. The effect of sampling and storage on the fecal microbiota composition in healthy and diseased subjects. PLoS One 2015; 10: e0126685.

20 Bacchetti De Gregoris T, Aldred N, Clare AS, Burgess JG. Improvement of phylumand class-specific primers for real-time PCR quantification of bacterial taxa. J Microbiol Methods 2011; 86: 351-356.

21 Rinttila T, Kassinen A, Malinen E, Krogius L, Palva A. Development of an extensive set of $16 \mathrm{~S}$ rDNA-targeted primers for quantification of pathogenic and indigenous bacteria in faecal samples by real-time PCR. J Appl Microbiol 2004; 97: 1166-1177.

22 Gagen EJ, Denman SE, Padmanabha J, Zadbuke S, Al Jassim R, Morrison M et al. Functional gene analysis suggests different acetogen populations in the bovine rumen and tammar wallaby forestomach. Appl Environ Microbiol 2010; 76: 7785-7795.

23 Wang RF, Cao WW, Cerniglia CE. PCR detection and quantitation of predominant anaerobic bacteria in human and animal fecal samples. Appl Environ Microbiol 1996; 62: 1242-1247.

24 Collado MC, Derrien M, Isolauri E, de Vos WM, Salminen S. Intestinal integrity and Akkermansia muciniphila, a mucin-degrading member of the intestinal microbiota present in infants, adults, and the elderly. Appl Environ Microbiol 2007; 73: 7767-7770.

25 Armougom F, Henry M, Vialettes B, Raccah D, Raoult D. Monitoring bacterial community of human gut microbiota reveals an increase in Lactobacillus in obese patients and Methanogens in anorexic patients. PLoS One 2009; 4: e7125.
26 Phielix E, Schrauwen-Hinderling VB, Mensink M, Lenaers E, Meex R, Hoeks J et al. Lower intrinsic ADP-stimulated mitochondrial respiration underlies in vivo mitochondrial dysfunction in muscle of male type 2 diabetic patients. Diabetes 2008; 57: 2943-2949.

27 Cardona F, Andres-Lacueva C, Tulipani S, Tinahones FJ, Queipo-Ortuno MI. Benefits of polyphenols on gut microbiota and implications in human health. $J$ Nutr Biochem 2013; 24: 1415-1422.

28 Dominianni C, Sinha R, Goedert JJ, Pei Z, Yang L, Hayes RB et al. Sex, body mass index, and dietary fiber intake influence the human gut microbiome. PLoS One 2015; 10: e0124599.

29 Flores R, Shi J, Fuhrman B, Xu X, Veenstra TD, Gail MH et al. Fecal microbial determinants of fecal and systemic estrogens and estrogen metabolites: a crosssectional study. J Transl Med 2012; 10: 253.

30 Markle JG, Frank DN, Mortin-Toth S, Robertson CE, Feazel LM, Rolle-Kampczyk U et al. Sex differences in the gut microbiome drive hormone-dependent regulation of autoimmunity. Science 2013; 339: 1084-1088.

31 Cho I, Blaser MJ. The human microbiome: at the interface of health and disease. Nat Rev Genet 2012; 13: 260-270.

32 Tyakht AV, Kostryukova ES, Popenko AS, Belenikin MS, Pavlenko AV, Larin AK et al. Human gut microbiota community structures in urban and rural populations in Russia. Nat Commun 2013; 4: 2469.

33 Zarrinpar A, Chaix A, Yooseph S, Panda S. Diet and feeding pattern affect the diurnal dynamics of the gut microbiome. Cell Metab 2014; 20: 1006-1017.

34 Marin L, Miguelez EM, Villar CJ, Lombo F. Bioavailability of dietary polyphenols and gut microbiota metabolism: antimicrobial properties. Biomed Res Int 2015; 2015: 905215.

35 Monagas M, Urpi-Sarda M, Sanchez-Patan F, Llorach R, Garrido I, Gomez-Cordoves C et al. Insights into the metabolism and microbial biotransformation of dietary flavan-3-ols and the bioactivity of their metabolites. Food Funct 2010; 1: 233-253.

36 Ley RE, Turnbaugh PJ, Klein S, Gordon Jl. Microbial ecology: human gut microbes associated with obesity. Nature 2006; 444: 1022-1023.

37 Dall'Asta M, Calani L, Tedeschi M, Jechiu L, Brighenti F, Del Rio D. Identification of microbial metabolites derived from in vitro fecal fermentation of different polyphenolic food sources. Nutrition 2012; 28: 197-203.

38 Bode LM, Bunzel D, Huch M, Cho GS, Ruhland D, Bunzel M et al. In vivo and in vitro metabolism of trans-resveratrol by human gut microbiota. Am J Clin Nutr 2013; 97: 295-309.

39 Calamini B, Ratia K, Malkowski MG, Cuendet M, Pezzuto JM, Santarsiero BD et al. Pleiotropic mechanisms facilitated by resveratrol and its metabolites. Biochem $J$ 2010; 429: 273-282.

40 Lambert JD, Sang S, Yang CS. Biotransformation of green tea polyphenols and the biological activities of those metabolites. Mol Pharm 2007; 4: 819-825.

41 Mahowald MA, Rey FE, Seedorf H, Turnbaugh PJ, Fulton RS, Wollam A et al. Characterizing a model human gut microbiota composed of members of its two dominant bacterial phyla. Proc Natl Acad Sci USA 2009; 106: 5859-5864.

42 Timmers S, Hesselink MK, Schrauwen P. Therapeutic potential of resveratrol in obesity and type 2 diabetes: new avenues for health benefits? Ann NY Acad Sci 2013; 1290: 83-89.

43 Kang C, Zhang Y, Zhu X, Liu K, Wang X, Chen $M$ et al. Healthy subjects differentially respond to dietary capsaicin correlating with the specific gut enterotypes. J Clin Endocrinol Metab 2016; 101: 4681-4689.

44 Larsen N, Vogensen FK, van den Berg FW, Nielsen DS, Andreasen AS, Pedersen BK et al. Gut microbiota in human adults with type 2 diabetes differs from nondiabetic adults. PLoS One 2010; 5: e9085.

45 Fernandes J, Su W, Rahat-Rozenbloom S, Wolever TM, Comelli EM. Adiposity, gut microbiota and faecal short chain fatty acids are linked in adult humans. Nutr Diabetes 2014; 4: e121.

46 Canfora EE, van der Beek CM, Goossens GH, Jocken JW, Lenaerts K, Holst JJ et al. Colonic short-chain fatty acids infusions promote fat oxidation and improve metabolic parameters in overweight males. Obes Facts 2015; 8: Abstract.

47 Perseghin G, Scifo P, Pagliato E, Battezzati A, Benedini S, Soldini L et al. Gender factors affect fatty acids-induced insulin resistance in nonobese humans: effects of oral steroidal contraception. J Clin Endocrinol Metab 2001; 86: 3188-3196.

48 van de Wijgert JH, Verwijs MC, Turner AN, Morrison CS. Hormonal contraception decreases bacterial vaginosis but oral contraception may increase candidiasis: implications for HIV transmission. Aids 2013; 27: 2141-2153.

49 Karlsson F, Tremaroli V, Nielsen J, Backhed F. Assessing the human gut microbiota in metabolic diseases. Diabetes 2013; 62: 3341-3349.

50 Arumugam M, Raes J, Pelletier E, Le Paslier D, Yamada T, Mende DR et al. Enterotypes of the human gut microbiome. Nature 2011; 473: 174-180. 